\title{
Enhanced remote laboratory work for engineering training
}

\author{
Maarouf SAAD ${ }^{I}$, Radhi MHIRI ${ }^{1}$, Moustapha Dodo AMADOU ${ }^{1}$, Sandra SAHLI ${ }^{2}$, Saber OUERTANI ${ }^{3}$, Gérald \\ $B R A D Y^{4}$ and Vahé NERGUIZIAN ${ }^{I}$ \\ ${ }^{1}$ École de technologie supérieure, Montreal, Quebec, Canada \\ ${ }^{2}$ Cégep de Valleyfield, Quebec, Canada \\ ${ }^{3}$ Cégep de Sorel Tracy, Quebec, Canada \\ ${ }^{4}$ Cégep de Granby, Quebec, Canada \\ maarouf.saad@etsmtl.ca
}

\begin{abstract}
Today, with the development of digital equipment and the increased performances of Information and communication technology (ICT), the online laboratory or Lab At Distance (LAD) found an interesting tool in training systems and can also provide enrichment for the conventional laboratory.

In this paper, we present the experience of developing a set of LAD performed by the school of engineering École de technologie supérieure (ÉTS) in Montreal and three colleges (CEGEP) in Quebec.

From this experience, the article highlights both technical and pedagogical strengths. The different choices adopted for $L A D$ are discussed and a preliminary assessment of the operation of this set of LAD is also presented.

In addition to the beneficial sharing of facilities between institutions, new opportunities of ICT enrich the laboratory work and give it a new dimension. Visiting a Web site for an industrial application related to laboratory work allows contextualization of this work and gives more meaning to the work requested. The exploration of the technological characteristics of the equipment used can provide additional valuable learning.

These new technological possibilities coincide with the emergence of new learning approaches and raise questions about the potential role of laboratory work in the training of engineering students. The technopedagogy is currently revolutionizing the way traditional training by bringing the experience of the laboratory in the classroom, at home and in various locations. This also allows the student to be more in touch with the technological reality of the laboratory and even industrial space through virtual tours.
\end{abstract}

Keywords: Enriched remote lab: Lab at distance: Virtual tour: Learning approach: Information and Communications Technology (ICT).

\section{INTRODUCTION}

The economic development of Quebec is strongly linked to the availability of technical skills that provide continuity and support development in different industries.

Colleges (CEGEP) and institutions of engineering education are placed as key players in preparing future technologists and engineers and updating the knowledge of those who are already in the job market.

In the context of increasing demand for technical staff or shortage of skilled labor, the Federation of colleges (CEGEP) requests that colleges have the necessary leeway to update and adjust their training, and this in a short timeframe.

Young people are promoted and encouraged to these types of training. Graduates are in high demand and related trainings are characterized by appropriate practical training.

The problem is even more pronounced in regions where the dispersion of the population and the number of students wishing to engage in technical training is limited. Some courses requiring laboratory work may be abandoned due to the impossibility of grouping students in the same College to provide them with the necessary laboratory equipment.

Laboratory work is a fundamental component in the content of these technical training. The requirements of this work are increasing by the cost of equipment, the continuous development of technologies used in addition to the time, space and personnel mobilization needed for the realization of the laboratory work.

The project describes the development of a series of remote lab with an enhanced approach that allows the laboratory to meet the increasing demands and needs of academic institutions.

The paper is organized as follows: Section 2 describes the implementation of LAD project. Section 3 gives the enhanced LAD approach. Experimentation and conclusion are given in sections 4 and 5 .

\section{LAD PROJECT}

In the era of the emergence of information and communication technologies, laboratory work can and 
should be an element of attraction for young people to technical fields.

Within the framework of university-college collaboration, École de technologie supérieure (ETS) and colleges (CEGEPs) of Sorel-Tracy, Valleyfield and Granby have collaborated on a project with the aim to validate the feasibility of a virtual learning platform based on remotely controlled real hardware.

Activities in this project have enabled college teachers to take ownership of the technology developed by ETS for remote use of laboratory equipment and therefore, remote labs (LAD) were implemented in the three colleges. In addition, each college developed six learning scenarios within the same family of courses (in the Industrial Electronics Technology curriculum) offered at three colleges.

Each of the three CEGEPs completed 6 LAD prototypes. Teachers have tried out this developed LAD experiments with various groups of students.

The project for a period of three years ended in April 2013.

This project has led participants to consider various issues to be addressed including:

- The topology of technological devices used

- The information exchange and communication between different elements

- The appropriate user interfaces

- The choice of subject laboratory on a course and using equipment that can be controlled digitally

- The procedure for carrying out laboratory activities

- The support for the documentation, instructions and help

- The actual viewing of distant laboratory and the evolution of relevant variables

- The reservation scheduling for a secure access.

From this experience, the article highlights both technical and pedagogical strengths. Different choices adopted for LAD are discussed and preliminary assessment of the operation of this set of LAD is also presented.

\section{ENHANCED LAD}

The facilities provided by ICTs contributed greatly to the development of distance education. With the current technical performance of web, ICT is now able to open the horizons for effective realization of laboratory work remotely. Our challenge was to take advantage of these tools to enhance laboratory work and compensate for the lack of manipulation and direct contact with the laboratory equipment.
We sought to take advantage of these facilities to strengthen the link between theory, practice and industrial applications. Our concern was also to increase student's motivation and help them discover more about the specifications of the equipment used.

Figure 1 shows targeted objectives and solutions introduced to achieve them.

\section{Pedagogical approach}

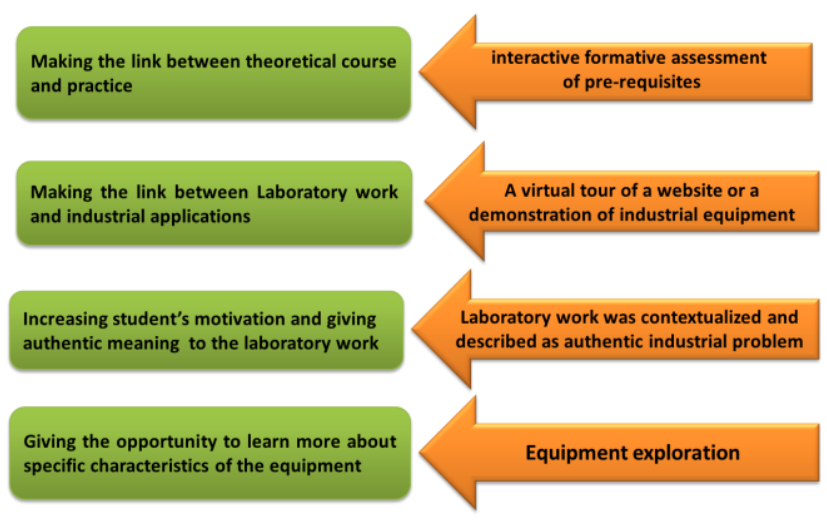

Fig. 1. Targeted objectives and solutions introduced.

In our project, we were inspired by the Problem Based Learning (PBL) approach. This approach had its beginnings at the Faculty of Medicine at McMaster University to the year 1960/1970 [1].

Over the time, the method conquered other fields and has attracted the attention of specialists in education. PBL is a teaching method focused on the student; it seeks to develop more efficient and faster reasoning and critical thinking than traditional teaching methods [2].

The problems of PBL are defined as authentic situations for students, based on their knowledge, recognize new concepts or those that are deficient in order to reconstruct, through the acquisition of new information, their knowledge [3].

PBL method promotes the anchoring of knowledge in long-term memory, the development of learning strategies and autonomy to encourage and support continuous learning [4].

Contextualization, authenticity of academic activity as well as collaborative work in small groups should help creating and maintaining student's motivation. Learners can develop personal and interpersonal skills such as autonomy, communication, cooperative work within a team [5].

The availability of ICT prompted us to develop and test new approaches combining PBL and ICT $[6,7]$. Usually, the laboratory comes in last step to allow verification or application of theoretical concepts. Educational benchmarks that we have described 
previously directed us to look in the laboratory an opportunity to enrich and enhance the traditional learning. We sought, by harnessing the power of ICT to enhance the work of LAD by the discovery of experiences and the use of real-world environments (remotely located). These learning conditions will serve as benchmarks for introducing practical work for students.

Thus, in a first step, the student is required to take a virtual (or industrial) tour by visiting a website or viewing a video clip that allows him to discover an industrial reality related to laboratory subject. This visit places the student in a real context about which the problem to be addressed is defined.

Thus we meet the characteristic of authenticity of the task that characterizes the PBL and can give meaning and legitimacy to the work. The student is expected to solve real problems or issues close enough to his future professional reality

Usually, in the laboratory, the problem to be treated is presented with a textual description (in text form). The availability of web access through LAD permits setting challenging and realistic context.

The student is then led to discover a problem derived from an industrial reality described by the image and video from the virtual tour. In a second step, the availability of the actual physical equipment for laboratory work, allows to handle and experience real and practical solutions.

We also exploit the potential of ICT to enable the deepening of some technological aspects on the equipment used. The student is then guided to websites of equipment manufacturers exploring the specifics of some real equipment which are illustrated and discussed so abundantly.

A website has been developed to guide the student in the learning path. The site includes three major phases:

- Pre-LAD: this stage is designed to take a virtual tour, ensuring that the student masters basic prerequisites and discovers the specific hardware used

- LAD Task: this is the most delicate stage. In this stage the student will be connected in real time to the laboratory equipment to conduct the remote experimentation. The time required for this stage is very critical and it must be minimized to allow all students handling the experiment in turns

- Post-LAD: stage allows students to analyze the results and submit the final report

In addition to the beneficial sharing of facilities between academic institutions, new opportunities of ICT enriched laboratory work and gave it a new dimension.

These new technological possibilities coincide with the emergence of new learning approaches and raise questions about the potential role of laboratory work in the training of engineering students. The techno-pedagogy is currently revolutionizing the way traditional training by bringing the experience of the laboratory in the classroom, at home and in various locations. This also allows the student to be more in touch with the technological reality of the laboratory and even industrial space through virtual tours.

\section{EXPERIMENTATION}

Utilization of developed LAD is conducted at the three College locations. Cross experiments were also conducted to validate the relevance of the network approach (Figure 2).

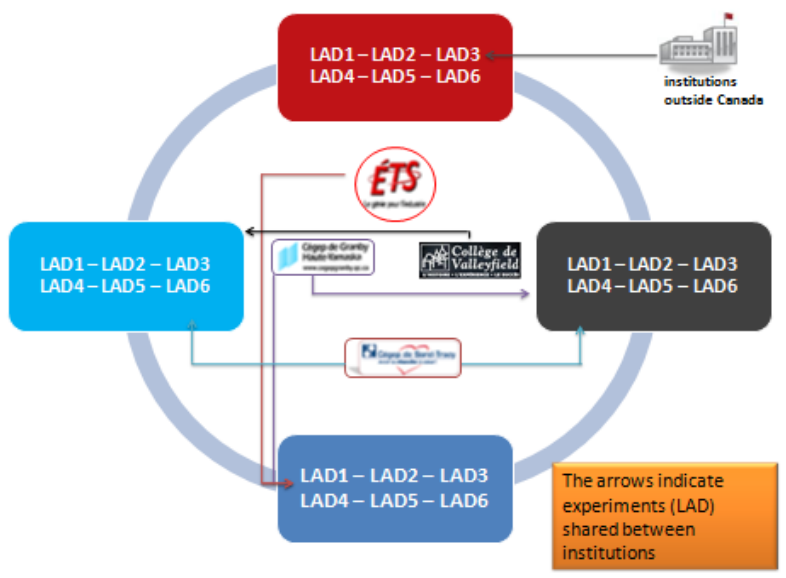

Fig. 2. Cross experiments between academic institutions.

Oral feedback from students was collected. Some written surveys were also conducted. Table 1 represents a sample of results related to innovative points of the approach. $(+++)$ indicates that the element is highly appreciated and (-) indicates that the element is not appreciated at all.

\begin{tabular}{|l|c|c|c|c|}
\hline & +++ & ++ & + & - \\
\hline Virtual Tour & $31 \%$ & $46 \%$ & $23 \%$ & \\
\hline Testing of pre-requisites & $12,5 \%$ & $75 \%$ & & $12,5 \%$ \\
\hline Equipment exploration & $46 \%$ & $38,5 \%$ & $15,4 \%$ & \\
\hline Elementary test & $18,2 \%$ & $63,7 \%$ & & $18,2 \%$ \\
\hline
\end{tabular}

Users have particularly appreciated the following points:

- Flexibility of the working place and period of time

- Accessibility to additional material

- Development of student's autonomy.

Users have given relevant critics about certain details such as: 
- Complexity due to the use of several software program at the same time

- Need of more indications about the way to use set-ups

- Lack of direct communication with tutors.

\section{CONCLUSION}

This article describes the orientations chosen for the development of the project "LAD of ETS-College Network". Internet facilities are used to enrich the LAD allowing the student to make the link between the work of the LAD and similar industrial applications. The presentation of the required work is in the form of problem situation. This gives more authenticity and meaning to the work that the student has to perform. In our approach, ICT enable and motivate the student to check his previous theoretical knowledge and explore the technological characteristics of the equipment used. With this approach, the laboratory experiments are enriched, making them more engaging and most significant in the learning process. The first sets of operating LAD are promising. With technological evolution, this mode of laboratory is in the process to bring new solutions to the problems of space and time.

\section{Acknowledgment}

The authors would like to acknowledge the support of MELS (Ministère de l'éducation, du loisir et du sport) and of École de technologie supérieure.

\section{References}

[1] Barrows, H.S. (1996). Problem-Based Learning in Medicine and Beyond: A Brief Overview. New directions for teaching and learning, 68, 3-12.

[2] Feisel, L. D., Rosa, A. J., Journal of Engineering Education 2005, 94, 121-130.

[3] Kelson, A.C.M. et Distlehorst, L.H. (2000). Groups in Problem-Based Learning: Essential Elements in Theory and Practice. In D.H Evenson et C.E. Hrnelo (eds.), ProblemBased Learning - A Research Perspective on Learning Interactions, 67-185. New Jersey: Lawrence Erlbaum Associates Publishers.

[4] Delva, M.D., Woodhouse, S., Hains, R.V., Knapper, C. and Kirby, J.R. (2000). Does PBL Matter Relations Between Instructional Context, Learning Strategies, and Learning Outcornes. Advances in Health Sciences Education, 5(3), 167-177.

CEEA13; Paper 090

Montreal, QC; June 17-20, 2013
[5] Wankat, P.C.(2004). Analysis of the First Ten Years of the Journal of Engineering Education. Journal of Engineering Education, Vol. 93, No. 1, pp. 13-21.

[6] Mhiri, R., Saad, M., Nerguizian, V., Amadou, M. SaliahHassane, H., Ouertani, S., Sahli, S., Brady, G., La technopédagogie dans les travaux de laboratoire contribue à un meilleur apprentissage et davantage de motivation en science et en technologie, Association Internationale de Pédagogie Universitaire (AIPU 2012), Trois- Rivières, Quebec, Canada, 14-18 May, 2012

[7] Radhi Mhiri, Maarouf Saad, Moustapha Dodo Amadou, Gérald Brady, Saber Ouertani, Sandra Sahli, Hamadou Saliah-Hassane, Vahé Nerguizian, The experience of a collaborative project on remote laboratory: From development to operation, IEEE International Conference on E-Learning in Industrial Electronics, (ICELIE 2012), October 25-28, 2012, Montreal, Quebec, Canada. 